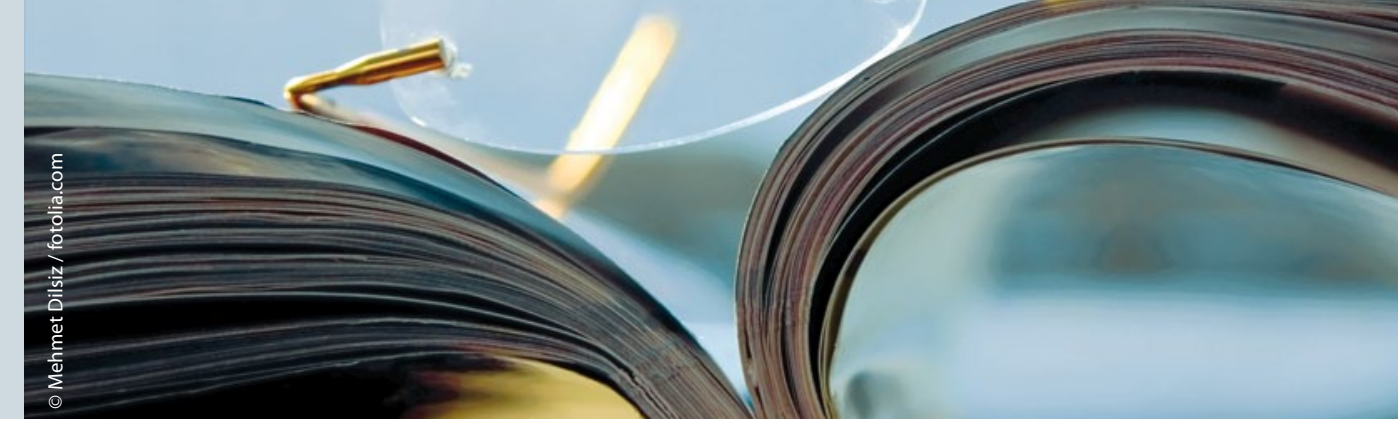

\section{Wie Schwangere Urinproben gewinnen sollten}

\author{
Schwangere müssen sich vor einer Urinprobe nicht besonders reinigen: \\ Bei einer gewöhnlichen Entnahme des Mittelstrahlurins ist das \\ Kontaminationsrisiko nicht erhöht.
}

E ine Harnwegsinfektion kann sowohl für die Schwangere als auch für den Fetus gefährlich werden, ein möglichst genauer Nachweis einer Bakteriurie ist daher essenziell. Normalerweise wird dafür Mittestrahlurin gewonnen. Den Frauen legt man oft nahe, dass sie vor dem Urinsammeln die äußeren Bereiche ihrer Geschlechtsorgane gut reinigen und während der Miktion die Schamlippen spreizen. Dies soll eine Kontamination des Urins und damit falsch positive Testergebnisse vermeiden. Allerdings ist eine solche möglichst sterile Uringewinnung gerade für Frauen mit fortgeschrittener Schwangerschaft nicht immer einfach.

Niederländische Gynäkologen haben nun untersucht, ob es auch ohne Reinigung geht: Bei 113 Frauen ab der 22 . Schwangerschaftswoche prüften sie den Mittelstrahlurin sowohl mit als auch ohne vorherige Reinigung, zudem analysierten sie den besonders konzentrierten Morgenurin. Die Frauen wurden also aufgefordert, morgens ihren ersten Urin zu sammeln und dann zusätzlich zweimal im Laufe des Tages, wobei sie nur bei einem der beiden Male versuchten, möglichst sterile Bedingungen einzuhalten. Damit konnten die Forscher um Schneeberger von jeder Frau drei Proben von einem Tag auswerten. Diese untersuchten sie anschließend per Bakterienkultur und Gramfärbung, wobei sie grampositive Stäbchen als nicht uro- pathogen werteten, bei grampositiven Kokken und gramnegativen Stäbchen aber von möglichen Uropathogenen ausgingen.

In der Gramfärbung ergaben sich keine konsistenten Unterschiede bei der Kontamination zwischen normal gesammeltem Morgenurin, normal gesammeltem Tagesurin und steril gewonnenem Tagesurin. Zwar waren Epithelzellen im Morgenurin etwas seltener nachweisbar (bei 50\%) als bei normal und steril gewonnenem Tagesurin (59\% und $57 \%$ ), die Unterschiede waren aber nicht signifikant. Der Anteil mit relevanten Epithelzellwerten lag in allen drei Gruppen unter 3\%. Ebenfalls nicht signifikant unterschieden sich die Anteile der Proben mit harmlosen grampositiven Stäbchen, potenziell pathogenen grampositiven Kokken sowie mit gramnegativen Stäbchen - diese Keime ließen sich in zwei Drittel bis vier Fünftel der Proben nachweisen. Wurde noch die Menge der nachgewiesenen Erreger berücksichtigt, so ergab sich nur bei den grampositiven Stäbchen ein Vorteil für die besonders saubere Uringewinnung.

Bei vier Frauen ließ sich in den Bakterienkulturen E. coli, bei einer Frau Proteus mirabilis und bei einer weiteren Schwangeren Pseudomonas nachweisen. E. coli ließ sich in allen drei Proben der jeweiligen Frauen nachweisen, Pseudomonas nur im normal gewonnenen Tagesurin, Proteus nur im Morgenurin.
Fazit: Egal wann und wie der Urin gewonnen wird, die Kontamination mit klinisch unproblematischen Keimen ist stets hoch, und die Kontamination mit klinisch relevanten Keimen unterscheidet sich nicht wesentlich. Daher genüge es, wenn Frauen ihren Mittelstrahlurin ohne besondere hygienische Vorkehrungen sammeln, auch müsse nicht extra Morgenurin getestet werden, denn damit seien die Ergebnisse auch nicht aussagekräftiger, schreiben die Studienautoren. Thomas Müller

Schneeberger $\mathrm{C}$ et al. Contamination Rates of Three Urine-Sampling Methods to Assess Bacteriuria in Pregnant Women. Obstet Gynecol 2013; 121:299-306

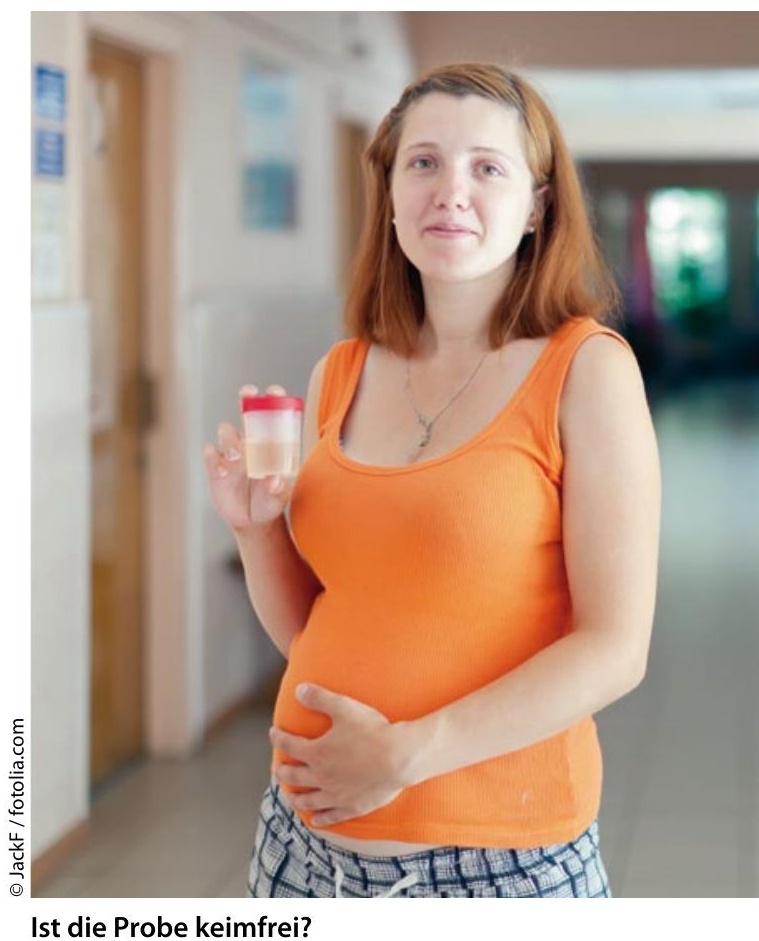

